\title{
Innovative train control systems based on ERTMS and satellite-public TLC networks
}

\author{
F. Rispoli ${ }^{1}$, A. Neri ${ }^{2} \&$ F. Senesi ${ }^{3}$ \\ ${ }^{1}$ Ansaldo STS, Italy \\ ${ }^{2}$ Radiolabs, Italy \\ ${ }^{3}$ RFI (Rete Ferroviaria Italiana), Italy
}

\begin{abstract}
The European Rail Train Management System (ERTMS) developed by the European industry represents a de-facto standard widely accepted in the world for signaling and speed-control applications. Whilst ERTMS has demonstrated its advantages as a cost-efficient train control system for high-speed lines and main corridors, the next challenge is to fulfill the emerging demand of low traffic lines for which the economical sustainability becomes a priority. Since an important share of the ERTMS operational costs are due to the telecommunication infrastructure and the wayside equipments, wireless IP-based telecom and satellite localization technologies are candidate to replace the costly fixed infrastructures. This paper discusses the scenario of local and regional lines in Europe and underlines the expected benefits brought by the adoption of the public cellular/satellite telecom network and the EGNOS-GALILEO satellite positioning system in the ERTMS ecosystem. A roadmap to validate the new technologies in the Italian Test Site is also presented.

Keywords: train control systems, ERTMS, satellite localization, cellular and satellite telecom, low traffic lines.
\end{abstract}

\section{Introduction}

Rail is a vital service and the transport backbone of a strong economy and the European Community has the objective, by 2020, to remove congestion from road. The efficiency of a railways line are reached by assuring at the same time 
the highest safety level by preventing human errors. This task is achieved with appropriate train control and supervision systems acting as Control, Command and Communication (CCC) systems developed for other operational scenarios like aviation, unmanned aerials, maritime and military operations. A CCC is the hearth of a modern train control system. It manages digital data communications, localization systems, sensors, and computers to guarantee the train circulation under safety conditions and raise effective capacity of the line.

The rail sector will benefit by the impressive technological developments being achieved in the wireless telecommunications and Global Navigation Satellite Systems (GNSS) being the enabling technologies of cost-efficient train control systems.

However, advanced train management systems, such as the ERTMS, that today represents de facto the railways signaling standard, being adopted worldwide, is used today only on the high speed/high capacity lines for which in the past there has been less pressure on identifying low-cost solution due to the high utilization rate of the assets and the numerous running trains and passengers transported. To "export" the ERTMS system on the low traffic lines (about 50\% of the total rail length in Europe) is of paramount importance to exploit the new technologies especially those which permit the "virtualization" of the telecom functions and of the train localization. Being the regional and local lines often over-aged and based on manual procedures under human control, their future is related to the availability of affordable and economically sustainable train control systems. Otherwise on these lines, the achieved performance of ERTMS is very difficult or even impossible to reach, at least without big investments in terms of money to spend and of time to realize them. Besides, the improvement of transport safety and economic efficiency on this kind of lines is an urgent need, otherwise, instead of attracting and transporting more passengers, several of these lines will be closed, as happened in the last twenty years, increasing more and more the big problems linked with the road traffic.

To improve the economics of the current ERTMS platform, but preserving its performance consecrated during many years of operations, the goal is to replace the costly trackside equipments for localizing the train and the dedicated telecom network with the GNSS and the IP-based telecom services. This evolution is already foreseen on the roadmap to enhance the ERTMS performance and included into the new ERTMS Memorandum [1] (Fig. 1).

In the USA, the Rail Safety Improvement Act of 2008, as enacted by Congress that affects most of the freight and passenger railroads has favored the introduction of satellite-based technology to implement a mandatory Positive Train Control (PTC) collision avoidance system by December 31st 2015 [2].

Other regions, such as Russia, China, and Australia have plans at different maturity stages to exploit the satellite and wireless telecom technology and this trend may accelerate the definition of a standard as it has been the case for the aviation sector with the initiative of the International Civil Aviation Organization (ICAO). For the telecom component, there is already a proposal for a standard, 
based on the PTC system. In this scenario the European rail stake-holders have set a roadmap to exploit the synergy between ERTMS and GNSS as strategic move to foster the European industry competitivity in the world [3, 4].

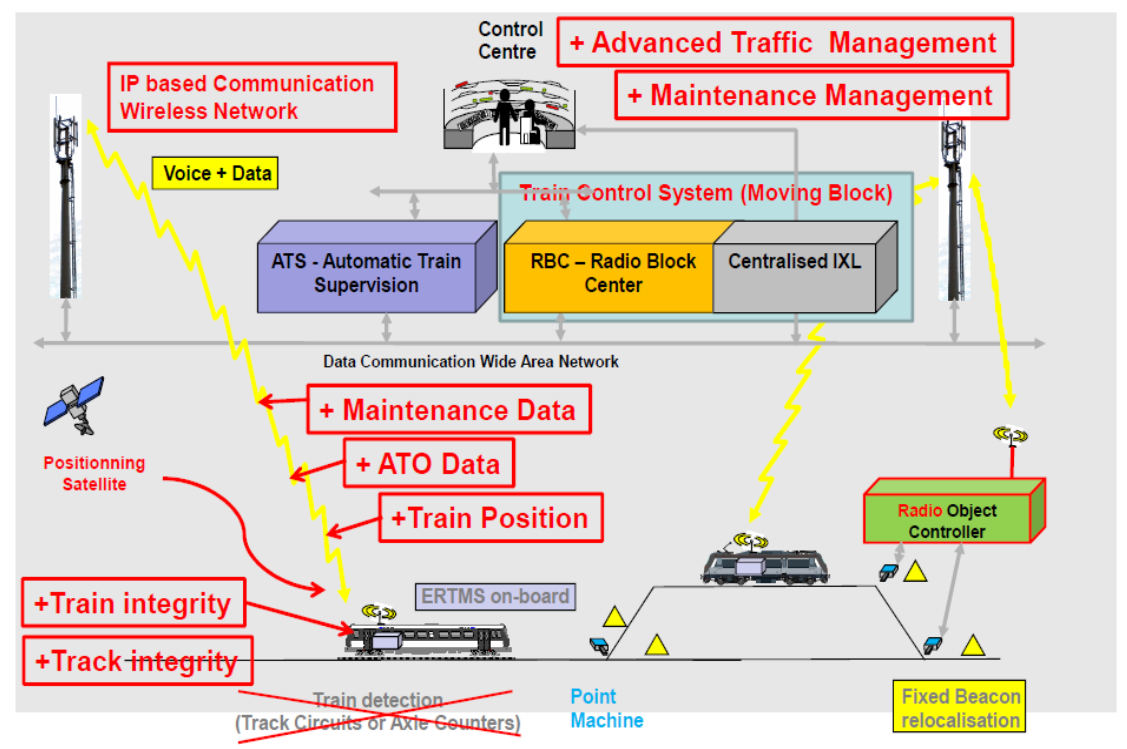

Figure 1: Reference architecture of the ERTMS platform and its evolution.

\section{System aspects}

Control, command and communication (CCC) systems are a key strategic technological capability for building network centric railway operations and intelligent railway systems. In a CCC system the timely, accurate, and trusted content of information between the different functions is a strategic asset and it lies at the heart of many network-centric operations. The aviation sector, for example, is transitioning from ground-based radar to satellite-based navigation and from analog voice communications to digital data exchange. Military drones already fly frequent missions and civilian operations using unmanned aircraft are coming. Driverless cars are clocking up thousands of test miles. The maritime industry is interested in crewless ships for two reasons. The first is safety. Most accidents at sea are the result of human error, just as they are in cars and planes. So, if human operators are replaced by sophisticated sensors and computer systems, autonomous vessels should, in theory, make shipping safer. The second reason is, of course, cost. It is becoming increasingly difficult to sign up competent crew prepared to spend months away at sea. Moreover, some voyages are likely to get even longer for ships carrying non-urgent cargo. By some accounts, a $30 \%$ reduction in speed by a bulk carrier can save around $50 \%$ in fuel $[5,6]$. 
Network-centric railways operations can reuse most of these technologies that are the core elements of a standard and trusted CCC platform (Fig. 2). This platform will ensure that the application using the system has access to a reliable and trusted information when needed and at an affordable cost. Starting with the general architecture of the ERTMS ETCS system, a high-level train management and control system foresees four interconnected functional blocs. A "trusted" service package cloud-based, should guarantee the quality for the GNSS signal and the connectivity.

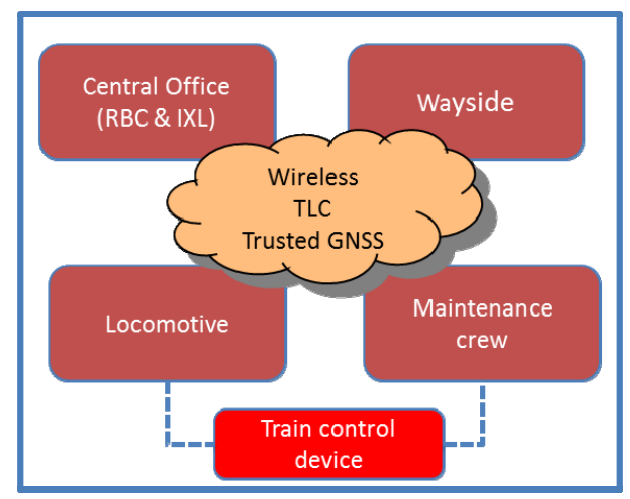

Figure 2: Block diagram of the rail CCC.

When the ERTMS specifications were issued, packet-switched data radios were not considered mature enough to carry safety-critical information. Therefore, all the original ERTMS standards are today based on circuit-switched data connections, and the requirements have been defined with a circuit-switched data connection in mind. However, circuit-switched data communications are inherently less efficient in terms of radio spectrum utilization (about 1-2\%) to cope with the traffic generated by the ERTMS L2 application. Low traffic lines are in principle less demanding in terms of packet rate because of the lower number of circulating trains and their maximum speed. Then the effectiveness of the GSM-R is even worse, in spite to the costs to install and operate a dedicated network. Moreover the GSM-R networks suffer congestion problems on large urban areas due to the insufficient $4-\mathrm{MHz}$ bandwidth allocation (19 carriers in total) and the limited number of carriers per cell. These constraints and the obsolescence of the GSM-R that is a technology introduced 25 years ago and since then three step-change innovations were introduced (Fig. 4), the search for for alternative telecom means is becoming now a priority [4]. Looking forward to endorse the telecom innovations, but with an eye to the ERTMS standard and the requirements of the local and regional networks, the dedicated telecom infrastructure concept may be replaced with the use of wireless IP-based telecoms and in particular with the public cellular and satellite networks (Fig. 5). Wireless telecoms have to guarantee the exchange of data between the locomotive and the Radio Bloc Center (RBC) and between the Interlocking (IXL) and the wayside object controllers. Assuming typical ground-to-train 
messages with payload of about 300 bytes issued every 3 seconds and train-toground messages of about 50 bytes payload every 4 seconds, such data volume doesn't play a significant role in the overall communication traffic. Other services, such as the emergency call, need to be managed as well.

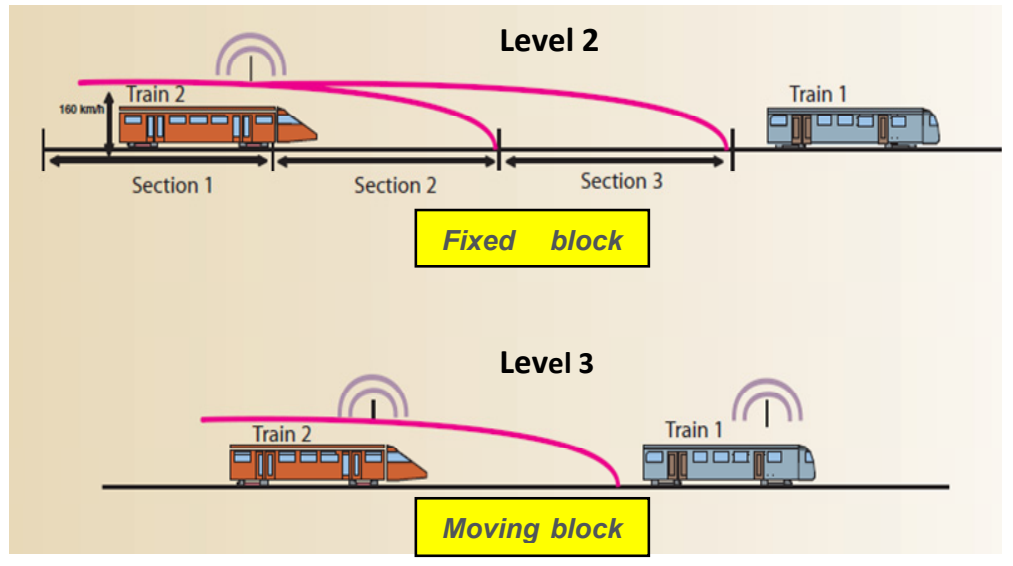

Figure 3: ERTMS level 2 and level 3 concepts.

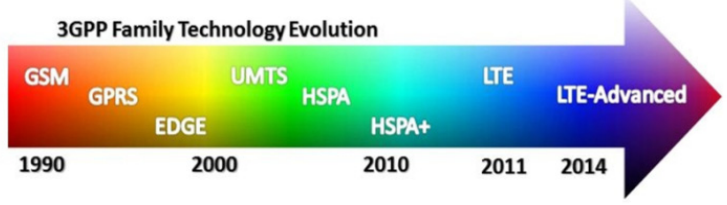

Figure 4: GSM technology evolution.

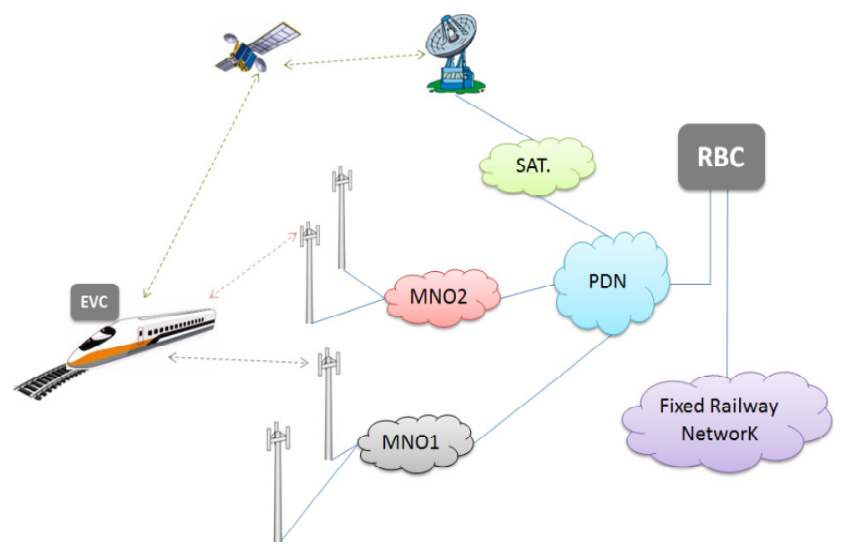

Figure 5: Multi-bearer multi-operator cellular/satellite infrastructure. 
If the GSM-R functions are provided by an integrated multi-bearer multi-operator cellular/satellite infrastructure, a dedicated ERTMS/ETCS communication infrastructure will not be needed. The train is connected to the Base Station of one or more Mobile Network Operators (MNO). The MNOs core networks interface with the $\mathrm{RBC}$ which receives/sends the Position Report and Movement Authority messages using one (or more) available $\mathrm{MNO}(\mathrm{s})$. This multi-bearer architecture has the flexibility to select the network as function of the outage and/or congestion of each network and ultimately to rely on the satellite that acts as a back-up in case none of the cellular networks is available. Moreover, the data could be transmitted in parallel on the different networks and discard the redundant packages on board the train. In other words the desired service level can be tailored ad-hoc for the rail applications as a bundling of different networks capabilities. The impact on costs becomes marginal since the KBytes exchanged are irrelevant respect to the high capacity offered by the public networks. This approach means that instead of procuring, installing, maintaining and operating a dedicated network, a service package can be negotiated with a telecom operator. The advantages are enormous in terms of capital cost savings and operations but also in the reduction of energy consumption that ultimately means about $60 \mathrm{~kg}$ per day per $\mathrm{km}$ of line less $\mathrm{CO} 2$ emissions.

Concerning the GNSS localization, the challenges are two: a) to reuse of the ETCS odometry by adding the virtual balise concept to eliminate the fixed balise along the line and b) to adopt the public EGNOS Augmentation network upgraded to fulfil the railways requirements. For the first issue the UNISIG Satellite Positioning Working Group was created in June 2012 to specify and standardize the application of the satellite positioning to ERTMS. One of the main objectives is to ensure that the impact on the existing system architecture and existing products can be kept minimal. The design of the localization system takes into account different satellite constellations, such as GPS, GLONASS, GALILEO and Beidou. The intelligent processing of the signals received by tens of satellites to safely localize the train is a powerful means to minimize the error and improve the localization availability in partially shadowed environment [8]. In this respect the use of a public augmentation network close to the standard of EGNOS is of paramount importance to preserve the interoperability requirement of the ERTMS system. However a number of studies have been developed to analyze the foundations of using the GNSS in the ERTMS ecosystem and to create a proper service compliant with the railways requirements and the results are encouraging [9-11]. Fig. 6 shows the generic train control system architecture, based on the ERTMS and with the new multi-bearer telecom capability and the GNSS localization means. In yellow there are the building blocks of the Augmentation Network based on EGNOS plus a 2nd tier Local network to fulfill the railways requirements [12]. In blue is marked the multibearer TLC network, while in green is underlined the Mobile Access Router responsible for the management of the different bearers. On board the train is possible to install standard Satcom, Cellular and Tetra devices depending on the specific line requirements. Tetra plus Satellite is foreseen for rural areas while 
Cellular plus Satellite is well suited for the regional and local lines. Fig. 7 shows the predicted GNSS Protection level (PL) to satisfy the SIL-4 safety requirement specified by the ERTMS). The PL varies along the line and it must be below the maximum allowed error that is defined the Alarm level (AL). The probability that the PL exceeds the AL and no-warning is given to the system must be lower than $10 \mathrm{E}-8 / 1$ hour in normal train operation.

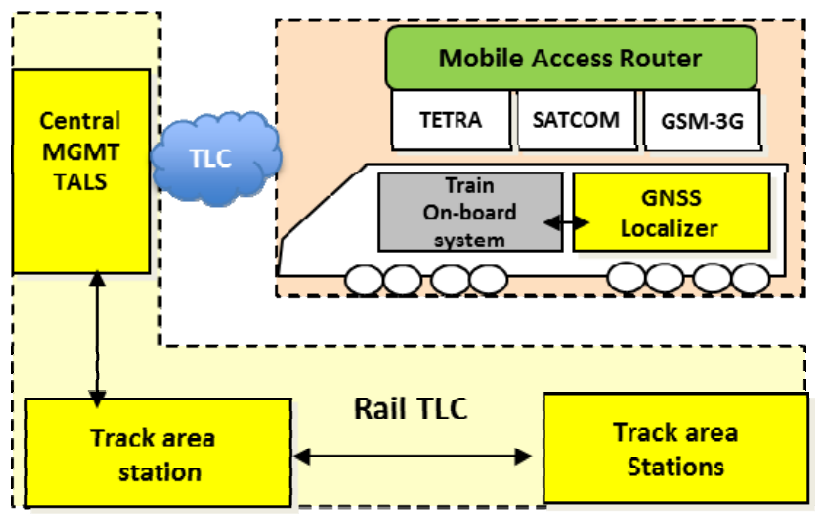

Figure 6: Reference ERTMS architecture with IP-Telecom and GNSS.

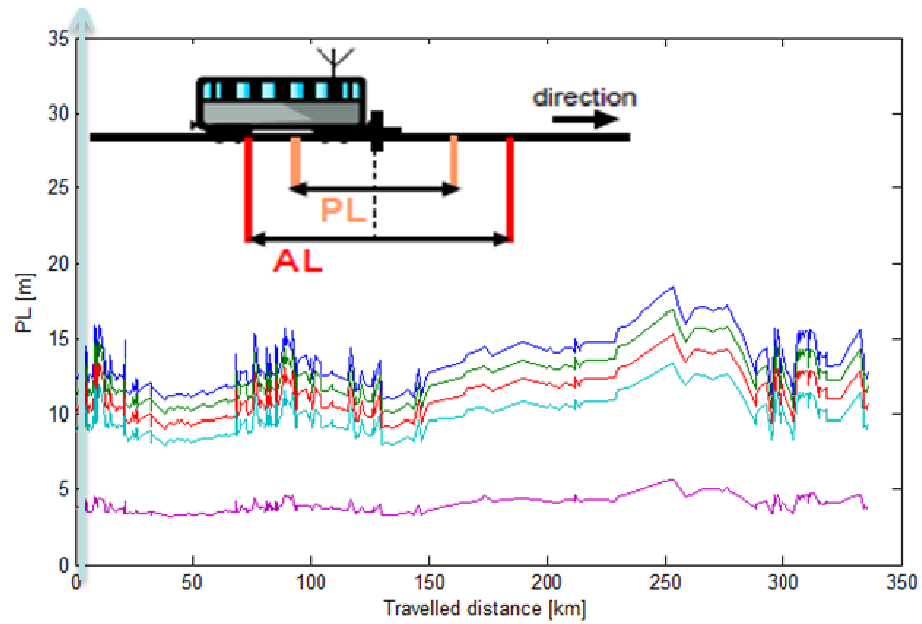

Figure 7: Protection level vs. travelled distance.

\section{Economical sustainability}

The endorsement of a new technology is generally a complex task especially when a step-change innovation is the strategic enabler. With the "injection" of public telecom and GNSS services into the ERTMS platform a shift from capex- 
operations to a capex-service model becomes inevitable. Most important is the assessment that the new technology will at the end bring benefits to the community. To this aim a Cost Benefit Analysis (CBA) is the tool used for identifying and monetizing the impacts of an investment decision in order to determine the project costs and benefits [13]. The aggregated results can support conclusions on whether the project is desirable and worth implementing. The application of CBA relies on the construction of a scenario analysis that identifies the costs and benefits in the project scenario as opposed to costs and benefits in a baseline scenario in which the envisaged investment does not take place, so that the running of rail operations continues with current technology and management. In particular, the differential elements of the project vs. the baseline scenario will be the adoption of the GNSS-based technology in ERTMS/ETCS systems in lieu of the current control and signalling systems, which vary depending on the lines. Therefore, in order to correctly assess the economic impacts of the introduction of satellite-based systems the approach has been to carry out detailed case studies and scaling up the results of case studies to the European level. For this purpose, national systems are grouped up into categories which are assumed to be reasonably homogeneous in terms of functionality and costs (Fig. 8). Basing on these categories, national railway networks are assigned to 4 different "types" of contexts which depend also on the envisaged evolution of the line in the concerned time horizon (Table 1). Unit costs and benefits per $\mathrm{km}$ are applied to the clusters of lines according to their types, yielding the following results. Overall, the introduction of ERTMS satellite in the Regional European Network generates benefits for some 35 billion Euros, with costs that sum up to 16 billion Euros in a 35-year time horizon. The overall Benefit/Cost Ratio is 2.2. For Type B contexts, the CBA has been calculated assuming that there are relevant upgrade plans for $20 \%$ of the concerned lines; the Benefit/Cost Ratio has been tested against the variation of such assumption. As shown in the Fig. 9, CBA proves to be positive in all cases.

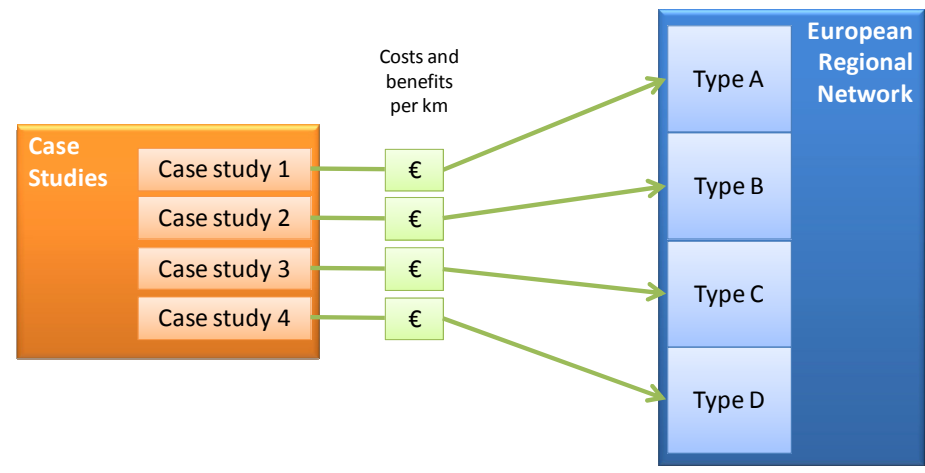

Figure 8: Case study segmentation. 
Table 1: Line length for each category.

\begin{tabular}{|c|c|c|}
\hline & Description & $\begin{array}{l}\text { Length of lines } \\
\text { (Selected countries in Europe) }\end{array}$ \\
\hline Type A & $\begin{array}{l}\text { - No protection } \\
\text { - Relevant upgrade envisaged } \\
\text { (whole network) }\end{array}$ & $53.089 \mathrm{~km}$ \\
\hline Type B & $\begin{array}{l}\text { - Basic protection (warning/stop) } \\
\text { - Relevant upgrade envisaged }\end{array}$ & $8.694 \mathrm{~km}$ \\
\hline Type C & $\begin{array}{l}\text { - Basic protection (warning/stop) } \\
\text { - No relevant upgrade envisaged }\end{array}$ & $34.776 \mathrm{~km}$ \\
\hline Type D & $\begin{array}{l}\text { - High protection (discrete s.v. +) } \\
\text { - No relevant upgrade envisaged }\end{array}$ & $65.254 \mathrm{~km}$ \\
\hline
\end{tabular}

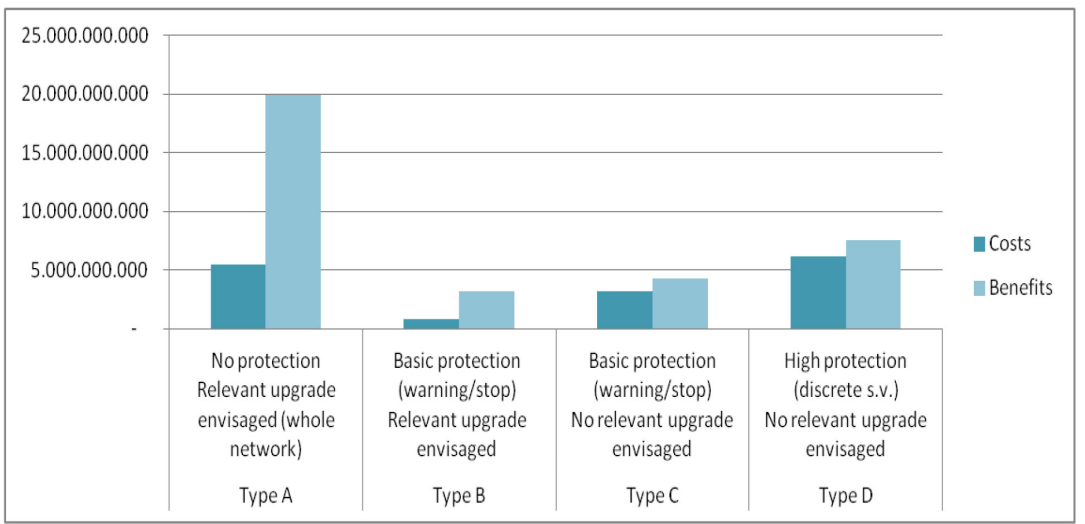

Figure 9: Comparison of costs and benefits of the project for the European regional network (selected countries) by type of context. Source: Bocconi University (Certet, 2013).

\section{Test and validation}

The verification and validation activities will be carried out on a Test site located in Sardinia on the Cagliari-Oristano line (Fig. 10). This activity is part of the on-going 3InSat project and the ERSAT initiative [14]. The first phase includes the test on the cellular and satellite TLC subsystem and the localization subsystem. In a second phase the ERTMS platform will be tested by integrating the TLC and GNSS components. This validation campaign represents a fundamental step to fine tuning the overall design before to activate a dedicated pilot line and support the standardization process. The Test site is also an indispensable tool to validate the Augmentation network for the satellite localizer and, in this respect, various architectures based on the EGNOS and dedicated Local networks will be tested. One important outcome is the characterization of the GNSS within the rail environment to help define the 
achievable performance in various operational scenarios. This task is crucial for supporting the on-going activities with the working group set by the UNISIG to define standardized procedures for GNSS signals quality determination in the railway environment and to perform safety analyses on potential impact of satellite navigation. The final results will be useful to understand the impacts and actions to be undertaken by the EGNOS stake-holders in order to make it compliant with the ERTMS needs.
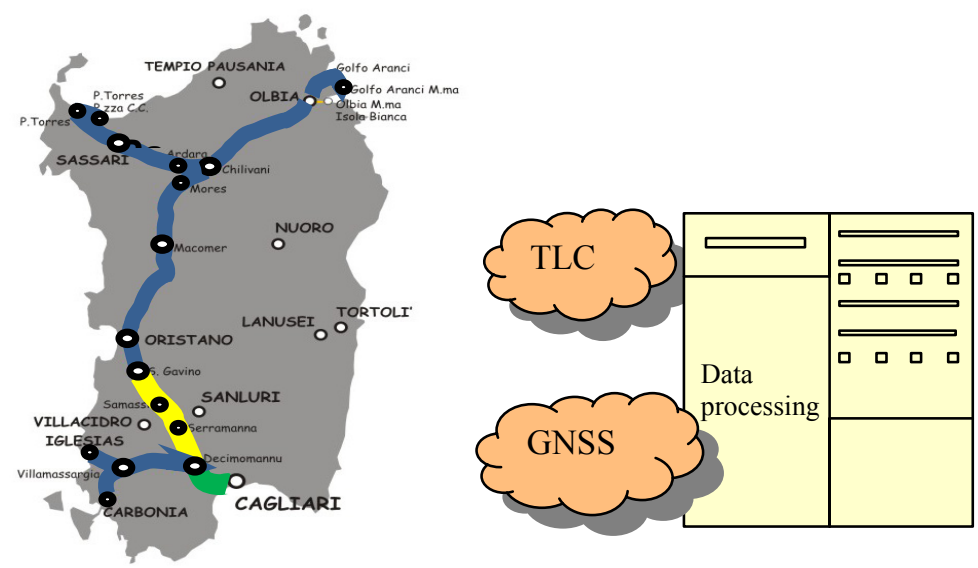

Figure 10: $\quad$ Test site.

\section{Conclusions}

This paper has presented an innovative train control systems based on the ERTMS standard with the introduction of the satellite localization and the utilization of the public TLC networks. The benefits brought by these innovations are a lower life cycle cost that ultimately will make the investments more sustainable to respond to the demand of the low traffic lines. A Cost Benefit Analyses has outlined the potential economical implications and industrial returns for both the Railways and the Satellite stake-holders. By the beginning of 2014 a test campaign will be carried out in a specific Test Site located in the Cagliari-Oristano line of Sardinia, starting first with the validation of the satellite and telecom technologies and culminating in the 2015-2016 with the validation of the entire end to end ERTMS platform.

\section{References}

[1] Memorandum of Understanding (MoU) between the European Commission, the European Railway Agency and the European Rail sector Associations (CER-UIC-UNIFE-EIM-GSM-R Industry Group-ERFA) 
concerning the strengthening of cooperation for the management of ERTMS. April 2012.

[2] Federal Rail Safety Improvements, Public Law 110-432-OCT. 16, 2008. PTC program.

[3] Task Group amendment to the existing IEEE 802.15.4 standard to expand its use for sensor, control and information transfer applications specific to rail and rail transit. http://www.ieee802.org/15/pub/TG4p.html

[4] Draft conclusions of the brainstorming meeting of 2 July 2013, European Commission Directorate-General for Mobility and Transport.

[5] Sam Pullen, Managing Separation of Unmanned Aerial Vehicles Using High-Integrity GNSS Navigation, EIWAC 2013 Tokyo, Japan. http://waas.stanford.edu/papers/SeparationforUAVNetworksEIWAC2013 final.pdf

[6] Autonomous cargo vessels could set sail without a crew under the watchful eye of captains in shore-based simulators. Mar 8th 2014, The Economist. http://www.economist.com/news/technology-quarterly/2159 8318-autonomous-cargo-vessels-could-set-sail-without-crew-under-watch ful-eye? $\mathrm{frsc}=\mathrm{dg} \% 7 \mathrm{Ca}$

[7] E. Del Signore, R. Giuliano, F. Mazzenga, M. Petracca, M. Vari, F. Vatalaro, A. Neri, F. Rispoli. On the Suitability of Public Mobile Networks for Supporting Train Control/Management Systems. IEEE WCNC'14 Conference, Istanbul 6-9 April 2014.

[8] A. Neri, A. Filip, F. Rispoli, and A.M. Vegni, "An Analytical Evaluation for Hazardous Failure Rate in a Satellite-based Train Positioning System with reference to the ERTMS Train Control Systems", in Proc. of ION GNSS 2012, September 17-21, 2012, Nashville, TN, USA.

[9] F. Rispoli, A. Filip, M. Castorina, G. Di Mambro, A. Neri, F. Senesi, "Recent progress in application of GNSS and advanced communications for railway signalling“, Radioelektronika (RADIOELEKTRONIKA), 2013 23rd International Conference, pp. 13, 22, 16-17, April 2013.

[10] A. Neri, V. Palma, F. Rispoli, and A.M. Vegni, "Track Constrained PVT Estimation based on the Double-Difference Technique for Railway Applications", in Proc. of EUSIPCO 2013, September 9-13, 2013, Marrakech, Morocco.

[11] A. Neri, A. M. Vegni and, F. Rispoli, "A PVT Estimation for the ERTMS Train Control Systems in presence of Multiple Tracks", in Proc. of ION GNSS 2013, September 16-20, 2013, Nashville, TN, USA.

[12] A. Filip, F. Rispoli. Safety concept of GNSS based train location determination system SIL 4 compliant for ERTMS/ETCS. ENC-2014, 14-17 April 2014, Rotterdam, The Netherlands.

[13] Economic evaluation of the introduction of GNSS technologies on the Train Control Systems. University Bocconi, Milan, Italy December 2013.

[14] 3InSat ESA Contract $N^{\circ} 4000105788 / 11 / \mathrm{NL} / \mathrm{NR}$. http://iap.esa.int/projects/transport/3insat 